\title{
Marginalidad indígena: una perspectiva histórica de Yucatán*
}

\author{
Pedro Bracamonte y Sosa y Jesús Lizama Quijano
}

La marginación y la pobreza son realidades que han acompañado a la población maya de Yucatán y que se han agravado en las últimas décadas. Éstas pueden ser consideradas como resultado de dos políticas gubernamentales que se han aplicado a lo largo de la historia a la población maya yucateca: la segregación colonial y el integracionismo nacional. Ambas constriñeron a los portadores de la cultura maya al ejercicio de su riqueza cultural en el ámbito estrictamente local, sin facilitar un intercambio cognoscitivo amplio con el exterior. Este trabajo analiza, en el largo plazo, la relación entre cultura y marginación entre los mayas de Yucatán, presentando primero un panorama histórico del grupo y, después, a través de los datos que aportan las fuentes estadísticas, una evidencia de las precarias condiciones de vida de los mayas yucatecos.

Marginalization and poverty are realities which have accompanied the Mayan population of Yucatán and which have worsened over recent decades. They can be considered as the result of two government policies which have been applied throughout the history of the Yucatecan Maya population: colonial segregation and national integrationism. Both forced the bearers of the Mayan culture to exercise their cultural wealth in the strictly local sphere, without facilitating the broad cognitive exchange with the outside. This article analyzes, over the long term, the relationship between culture and marginalization among the Yucatan Mayas, first presenting a historical overview of the group and then, through the data obtained from statistical sources, evidence of the precarious living conditions of the Yucatecan Mayas.

PEDRo BRACAMONTE Y SOSA Y JESÚs LIZAMA QUiJANO: CIESAS-Programa Peninsular.

Desacatos, núm. 13, invierno 2003, pp. 83-98.

* Este artículo es un producto del proyecto de investigación "Espacios de reproducción cultural y la construcción histórica de la marginalidad indígena en Yucatán, siglos XVI-XXI" que se desarrolla en el Programa Peninsular del CIESAS. 
$\mathrm{E}$ lobjetivo de este artículo es analizar en el largo plazo la relación entre cultura y marginación en el ámbito maya yucateco. En la actualidad, en este grupo, al igual que en otros de origen mesoamericano, se presenta una seria contradicción en el proceso de socialización pues éste conlleva referentes de mundos distintos que han mantenido entre ellos relaciones asimétricas y que condicionan la integración del individuo a la sociedad regional en una situación de franca desventaja. La posibilidad que podrían tener los mayas de ampliar su mundo de vida al manejar referentes culturales diversos se cancela tajantemente porque la sociedad regional ha construido, a lo largo de su historia, una situación estructural de subordinación fincada en gran medida en la diferencia cultural. ${ }^{1}$

La población maya del estado de Yucatán presenta características que pueden ser vistas como paradójicas. Por un lado este grupo étnico es portador de elementos culturales distintivos que lo han calificado como un colectivo con fuerte definición identitaria y con formas propias de organización social, pero al mismo tiempo padece y ha padecido desde la conquista — consumada entre 15411543- una situación caracterizada por la pobreza y altos niveles de marginación económica y social. En la realidad cotidiana que viven los mayas yucatecos subsisten los mecanismos sociales que inciden en los principales espacios de reproducción cultural —como la educación formal, la religiosidad y el ámbito laboral—y han producido a lo largo de cinco siglos los niveles de pobreza y marginalidad en casi todos los órdenes de la vida económica y social.

\footnotetext{
1 Berger y Luckmann (1998: 164-174) afirman que es a través de los procesos de socialización como los individuos aprehenden el mundo circundante - el "mundo de la vida cotidiana" o "mundo de vida"como propio. Por medio de la socialización primaria un individuo llega a ser considerado - y a considerarse - como parte de una sociedad. Solamente es posible observar la internalización de las estructuras objetivadas cuando los individuos logran identificar su ubicación en un mundo determinado y, por eso mismo, adoptan no sólo diversos roles sino también el mundo en el que estos roles tienen significado objetivo. La socialización secundaria consiste en el aprendizaje de un conocimiento especializado relativo a un sector específico de ese mundo social. En ella se asumen realidades parciales de la sociedad en que el individuo se encuentra inmerso. A estos procesos también se les ha denominado "enculturación (Herkovits, 1969) o bien, "educación" (Mead, 1976).
}

\section{POLÍTICAS DE SEGREGACIÓN E INTEGRACIÓN: UN MISMO RESULTADO}

La identificación entre etnicidad y marginación se gestó como requisito — a la vez que resultado — de la colonización española, así como del proceso de formación neocolonial del Estado-nación. Estos largos periodos están definidos por políticas antagónicas con referencia a la población indígena: el primero marcado por la segregación "racial" y cultural y el segundo por la integración a costa de la cultura, la lengua y la identidad. Un breve balance de la situación de los mayas previa a la conquista indica que la península de Yucatán contaba con una numerosa población con niveles de organización que le habían permitido generar una compleja sociedad y cultura, así como producir un volumen importante de excedentes económicos para sostenerlas. La civilización maya, a pesar de la fragmentación política y las rivalidades entre señoríos, mantenía vigentes sus principales logros culturales y era portadora de una cosmovisión y una religiosidad muy profundas compartidas con el área cultural mesoamericana. En el ámbito político y territorial, los mayas se adscribían a 16 señoríos o pequeños estados (cuchcabales, en maya) distintos, con diversos niveles de integración y cohesión social, que iban desde el poder centralizado hasta la alianza para la defensa frente a enemigos comunes (Roys, 1957).

Uno de los resultados más inmediatos del contacto indoeuropeo fue el descenso demográfico, pues la población maya-yucateca disminuyó drásticamente: de un cálculo de 800 ooo habitantes antes de la conquista, en 1550 se estimaba la población en 240000 personas; hacia 1736 la apreciación más optimista se sitúa en 127000 habitantes, y a fines de la época colonial, hacia 1809, los mayas yucatecos sumaban cerca de 300 ooo después de varias décadas de recuperación. Pero más allá del desastre demográfico, el concepto unificador y transformador de "indígenas" significó para los sobrevivientes de las epidemias tanto subordinación como discriminación "racial" y cultural derivadas de la idea europea de la "servidumbre natural", que dominó el pensamiento sobre el hombre americano después del famoso debate entre Ginés de Sepúlveda y fray Bartolomé de las Casas. En con- 
traste, la población no indígena, incluyendo españoles, mestizos y castas, tuvo un crecimiento demográfico muy lento, pues en 1550 estaba constituida por 1500 habitantes, y en 1700 apenas alcanzaba unas 21250 personas. En los inicios del siglo XIX representaba ya una cuarta parte de la población total y la mayoría restante era maya (García Bernal, 1978; Farriss, 1992: 105; Gerhard, 1991: 21; Cook y Borah, 1978, II: 119); los españoles peninsulares y criollos continuaban siendo una pequeña minoría. En 1974, en Mérida, sumaban 3412 individuos frente a 14751 mayas y 9666 mulatos y miembros de las llamadas castas (AGN, Historia, vol. 522, núm. 39).

Los señoríos mayas conquistados fueron reorganizados por los colonizadores en cerca de 240 repúblicas indígenas, una forma de institución político-territorial que es el precedente inmediato de los municipios contemporáneos. En los pueblos cabecera de esas repúblicas se instauró el cabildo de origen castellano pero se registró una continuidad en diversas formas de liderazgo indígena, aunque circunscritas al ámbito local (Roys, 1943). La política estatal de segregación permitió esta continuidad en el ejercicio del poder municipal al otorgar a los dirigentes de cada república de indios la capacidad de gestión de sus propios recursos territoriales, fiscales y humanos, así como un gobierno propio (Farriss, 1992: 144-160), aunque fueron marginados de los cargos de la administración provincial. Las repúblicas dispusieron, entonces, de territorios de jurisdicción política y en su interior existieron tierras comunales y privadas, estas últimas en dos modalidades: de los linajes patrilineales (ch'ibales en maya) y de los individuos (Bracamonte, 2003).

En el ámbito de la economía, el trabajo organizado de los mayas se convirtió en la principal fuente de riqueza para los conquistadores ante la falta de minas y tierras propicias para cultivos comerciales (Farriss, 1983: 125-128; García Bernal, 1972: 2-4; Patch, 1993: 9-13).

Así, Yucatán quedó fuertemente integrado al régimen colonial en la esfera del comercio exterior por medio de la tributación, los servicios personales y los repartimientos, pero los mayas quedaron excluidos de una injerencia directa en las redes de esa actividad (Solís, 2003) y compelidos a vivir en el estricto marco social de sus repúblicas.
En lo que se refiere a dos de los espacios más importantes de los procesos de reproducción cultural, la educación y la religiosidad, ${ }^{2}$ hay que tomar en cuenta el papel determinante que en estos ámbitos desempeñaron la Iglesia como institución y sus miembros, primero los franciscanos y luego los miembros del clero secular. Hay que aclarar que la colonización desarticuló los mecanismos formales de trasmisión del conocimiento de los señoríos mayas, al tiempo que se avanzaba en la cristianización. Bajo la responsabilidad de la Iglesia quedó el registro puntual de la población, necesario para tasar tributos, limosnas, montos de repartimiento y asignaciones de servicio personal, pero la misión más importante fue evangelizar y vigilar que la vida espiritual se ajustara a los cánones del cristianismo, poniendo énfasis en la instrucción de los menores. Al interior de los pueblos de indios se enfrentaron dos cosmovisiones - la maya y la europea- que, a pesar de mantener ciertos espacios excluyentes, también coincidieron y se integraron sincréticamente en diversos aspectos de la vida religiosa como se hace patente en las denominadas idolatrías que, aunque perseguidas, siempre tuvieron un espacio autónomo en la vida indígena (Solís, 2003).

Aunque la compleja evangelización —eje de la educación formal durante la Colonia — estuvo asociada directamente a la socialización de los menores en un nuevo contexto de dominación, la continuidad del uso de su lengua y la adopción de caracteres latinos para escribir en maya contribuyeron a mantener importantes ámbitos de expresión propia que abarcaron el hogar, la república y la región, aunque mucho de ese conocimiento, especialmente el relativo a la vida ritual y religiosa, a la cosmovi-

\footnotetext{
2 La educación y la religiosidad son aspectos importantes dentro de la socialización primaria. A través de la primera, el individuo adquiere un conjunto de saberes propios de la sociedad en que vive (entre ellos la lengua), que le permite llegar a considerarse como parte de este grupo, en cuanto que son compartidos por los demás miembros. El conglomerado de creencias religiosas también se adquiere en esta etapa y coadyuva, entre otras muchas cosas, a que a los individuos puedan conducirse en un mundo vivido y experimentado como ordenado. Los procesos de socialización primaria se desarrollan durante la niñez, en el seno de la familia, donde se adquiere — dirían Berger y Luckmann (1998) — el "mundo base" que posibilitará las demás socializaciones que se desarrollan a través de instituciones oficiales.
} 


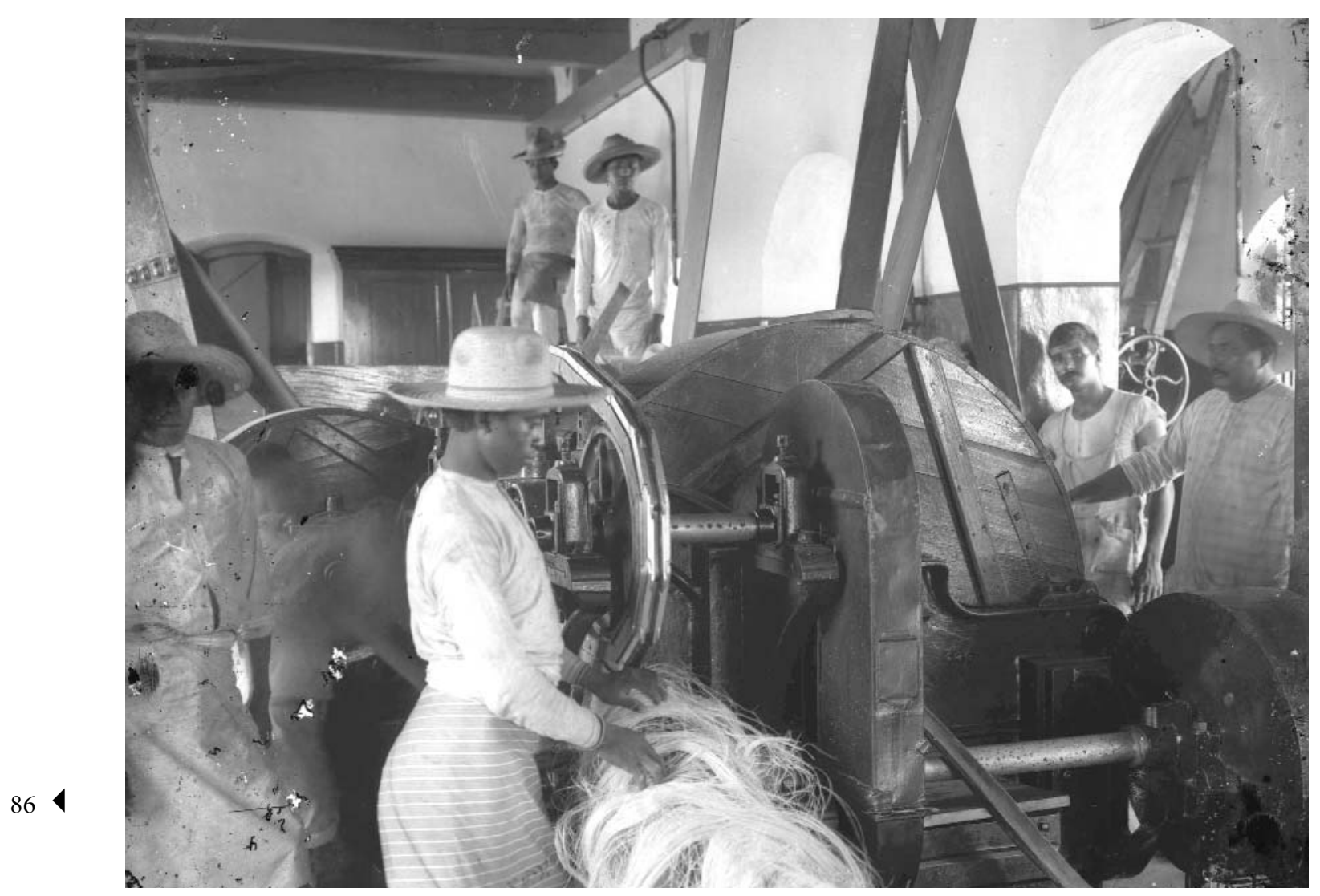

Máquina desfibradora de henequén, 1916 / Fototeca Pedro Guerra, Universidad Autónoma de Yucatán.

sión y a la historia, fue considerado proscrito y tuvo que desarrollarse en secreto. De modo que ejes trascendentales de la cultura propia se reprodujeron a pesar de los esfuerzos desintegradores, como fueron, por ejemplo, la concepción cíclica del tiempo, el uso de los calendarios de origen mesoamericano, el mito de la creación del mundo y el papel de los linajes en la organización social y política, tal y como se puede ver en el Chilam Balam de Chuma$y e l$, entre otros escritos mayas. La socialización inicial en el ámbito del hogar, tanto entre los miembros de la nobleza indígena como entre los macehuales, evidentemente realizada en lengua maya, fue el más importante resguardo tanto de la propia lengua como de la cultura y pilar de la continuidad identitaria en los siglos posteriores.

La tendencia al integracionismo fue ganando terreno a partir de las transformaciones registradas desde mediados del siglo XVIII, como resultado de modificaciones impulsadas desde Europa e inspiradas en el pensamiento liberal. Se pueden mencionar, por ejemplo, una exitosa política de enajenación de tierras baldías para impulsar el crecimiento de la agricultura y la ganadería empresarial (Farriss, 1992) y el fuerte empuje al ideal de la castellanización de la población indígena mediante cédulas reales que, empero, resultó inútil. La construcción de México como moderno Estado-nación durante el siglo XIX acentuó las transformaciones de la sociedad maya debido a la política general encaminada a la desamortización de las corporaciones civiles, como eran los pueblos, y a la proyectada ciudadanización de la población indígena.

Esta situación de integracionismo generó oposición en los pueblos y fue la causa íntima de dos graves conflictos sociales que han sido denominados en la historia regional como la rebelión de Jacinto Canek de 1761 y la guerra de castas entre 1847 y 1901. Otros cambios que afectaron 
negativamente a los mayas fueron la desaparición del Juzgado de Indios, la cancelación del uso legal de su propia lengua y el desarrollo de un nuevo sistema de elecciones de autoridades locales que los desplazó de los cargos de cabildos y juntas municipales en beneficio de la población no indígena (Güémez, 2001). Podemos decir que las instituciones sociales que habían normado la vida indígena perdieron todo sustento jurídico. Al cerrarse el siglo XIX, los haberes de las antiguas repúblicas de indios se habían perdido casi por entero, aproximadamente la mitad de la población maya habitaba en el interior de las haciendas henequeneras en calidad de peonaje asalariado. En los pueblos se habían estrechado sustancialmente los límites de las posesiones comunales o ejidales, a más de que un creciente mercado de la tierra condujo al tránsito de la propiedad privada indígena a manos españolas (Bracamonte, 1993 y 2002).

El siglo XX aceleró los cambios. En pueblos y villas creció una numerosa población mestiza muy cercana culturalmente a la sociedad maya, aunque sin los vínculos que ataban a los indígenas con sus antiguas y cuestionadas corporaciones. La industria agroexportadora del henequén, el comercio exterior, el crecimiento urbano de Mérida, la educación profesional, el acceso a la vida política y a los cargos y puestos públicos, entre otras actividades, constituyeron espacios preferenciales para esa población no indígena. Los mayas, cada vez más excluidos de esas áreas de la vida económica y social, no tuvieron otra opción que refugiarse en el cerrado ámbito de lo que la antropología dio en llamar la "vida comunitaria”, toda vez que desde el porfiriato se empezó a postular, como una meta nacional, la edificación de un México mestizo con una fuerte y única identidad. Frente al triunfo del nacionalismo en la edificación del Estado moderno, la "comunidad" fue asumida oficialmente como el ámbito de lo indígena, para no reconocer ya la existencia de una sociedad constituida. Empero, la lengua y la cultura propias permanecieron aún como un acervo vivo de riqueza y de identidad de la población maya y de la sociedad regional. En las últimas décadas del siglo XIX y las primeras del siglo XX ya se podía identificar un sistema de clientelismo político entre las élites criolla y mestiza y los habitantes de los pueblos (Wells y Joseph, 1996), un mecanismo que, reinventado por el régimen del nacionalismo revolucionario, todavía se puede observar en la actualidad y que constituye la más grave rémora en la edificación de la democracia política en la región.

La reforma agraria entre 1920 y 1960, si bien restituyó y dotó de tierras a pueblos y nuevos centros de población con mayoría maya, empleó como instrumento de control una figura jurídica de posesión de la tierra denominada ejido, que quedó atada y condicionada al Estado. La mayor parte de los mayas se adscribió a los ejidos colectivos impulsados por el cardenismo entre 1936 y 1940, en donde se renovaron antiguas formas corporativas de vida política. Sin embargo, el eje primordial de la política integracionista ha sido la educación pública en español. En los contenidos se privilegió la exaltación de la historia nacional de confección oficial y se dejó de lado el acervo de conocimientos derivados de la cultura maya que permaneció socialmente estigmatizada. La educación bilingüe contribuyó al proceso integrador. Así se explica que los datos agregados de población monolingüe maya para la península de Yucatán sean aproximadamente de 132000 habitantes en 1930, 114000 en 1940 y 91000 en 1960, lo que representa un evidente decremento (INI-PNUD, 2000, II: 571-573).

En términos generales se puede concluir que en la construcción de la marginalidad y de la pobreza de los mayas yucatecos la política de segregación impuesta por el régimen colonial desarticuló la organización política territorial, inició el cambio forzoso de las instituciones sociales y religiosas, articuló y aseguró la extracción de los excedentes factibles y estableció y obligó a la interiorización de un concepto ideológico de subordinación de origen "racial" y cultural derivado del imaginario de la "servidumbre natural" que asumieron los conquistadores para calificar a la población americana. El integracionismo como perspectiva política también contribuyó en mucho a arraigar la marginación y la pobreza, aunque por otras vías, entre las que hay que destacar la castellanización obligada y la escuela pública. Esta tendencia no cuestionó, como pudiera parecer, el concepto de la "servidumbre natural”, sino que, reconociéndolo, se planteó como meta la virtual desaparición de sus concreciones sociales, es decir, las culturas indígenas. 


\section{EL PRESENTE MAYA: POBREZA Y MARGINACIÓN}

Si bien han sido múltiples los factores que han influido en la vida de los mayas y producido cambios de diverso tipo al interior de las localidades que habitan, esta cultura conserva su vigencia, se reproduce de muy diversas maneras y mantiene su diferencia con respecto a la sociedad que la envuelve y constriñe. La vitalidad de la cultura maya en Yucatán es posible percibirla a través de la lengua, el vestido, las prácticas religiosas y las actividades económicas, entre otras muchas variables cuya reproducción en la vida cotidiana evidencia la permanencia de una sociedad diferenciada de la regional, a la que el proceso histórico por el que ha transitado ha proporcionado una configuración específica.

Los mayas de Yucatán habitan en los 106 municipios que conforman el estado, sin embargo su distribución no es homogénea sino que en cada uno de ellos presentan dinámicas diversas, pues existen algunos en los cuales son mayoría y otros en los que su presencia es relativamente mínima. ${ }^{3}$ Asimismo, las localidades con mayor número de población indígena en muchos casos no superan los cien habitantes, ${ }^{4}$ lo que dificulta la dotación de servicios básicos que, aunado a la falta de acciones y políticas de bienestar social, han mantenido a la población indígena en una espiral de marginación, haciendo que los términos "gente maya" y "pobre" sean considerados, en el ámbito regional mestizo, como sinónimos, produciendo dicotomías diversas como lo "tradicional" y lo "moderno" o "pobreza” versus "desarrollo", donde los primeros términos de cada una están relacionados con la población maya, y los segundos, con la regional o mestiza. Así, lo "tradicional", concebido en numerosas ocasiones como sinónimo de "atrasado" o "pobre", reside en esas localidades que han sido consideradas por mucho

3 Sobresale entre los primeros el municipio de Tahdziú, en el que el censo de 2000 registró que un $99.6 \%$ de la población total es mayahablante; en contraste se encuentra el municipio de Dzidzantún, en donde los hablantes de maya sólo representan el 7.9\% del total poblacional.

${ }^{4}$ Para el 2000, el XII Censo de Población registró en Yucatán la existencia de 3363 asentamientos, de los cuales 2748 (81.7\%) no sobrepasaban los 49 habitantes. tiempo como unidades corporativas cerradas, autónomas y autosuficientes, con poca o nula relación con el exterior y renuentes a aceptar elementos externos que pudieran propiciar un cambio en sus sistemas de producción y en sus modos de vida.

Sin embargo, los mayas nunca han estado aislados. A lo largo de su proceso histórico es posible observar cómo factores provenientes del exterior de sus localidades terminan afectando sus instituciones y sus formas de vida. Así, se adoptan elementos culturales externos, se reformulan e integran a la cotidianidad; lo mismo sucede con las reglas sociales, que asumidas y asimiladas son utilizadas de manera estratégica en busca del mantenimiento de sus campos de acción cultural, o para orientar su conducta en un mundo concebido como ordenado. De esta forma, los actores sociales han dado respuestas específicas a agentes externos y en una relación de íntima confrontación y contrastación recrean sus identidades y mantienen sus espacios de reproducción cultural. ${ }^{5}$

\section{LOS MAYAS EN CIFRAS}

Las formas en que los individuos se identifican a sí mismos conllevan una serie de problemas al momento de querer contabilizarlos como pertenecientes a un grupo étnico determinado, puesto que la identidad no viene dada por la naturaleza del sujeto sino que es una construcción social, por lo que posee su propia dinámica y varía dependiendo del contexto en el cual el individuo interactúa (Cardoso, 1992). 6 Así, la tradicional dicotomía entre sociedad indígena y sociedad mestiza no es de gran ayuda para ubicar claramente a los actores sociales puesto que los elementos empleados para ello se basan, principalmente, en cuestiones raciales, sean éstas el color de la piel, el tipo del cabello o fenotipos diversos; o en cate-

\footnotetext{
${ }^{5}$ Grimberg y Grimberg (1971: 136) han manifestado que uno de los elementos importantes para la consolidación del sentimiento de identidad era el juego dialéctico entre semejanza y diferencia.

${ }^{6}$ Melucci (1982) indica que entre los elementos principales a tomar en cuenta para comprender el problema de la identidad social se encuentran los procesos de autopercepción y heteropercepción, así como el sentimiento de perdurar en el tiempo y la conciencia de unidad.
} 


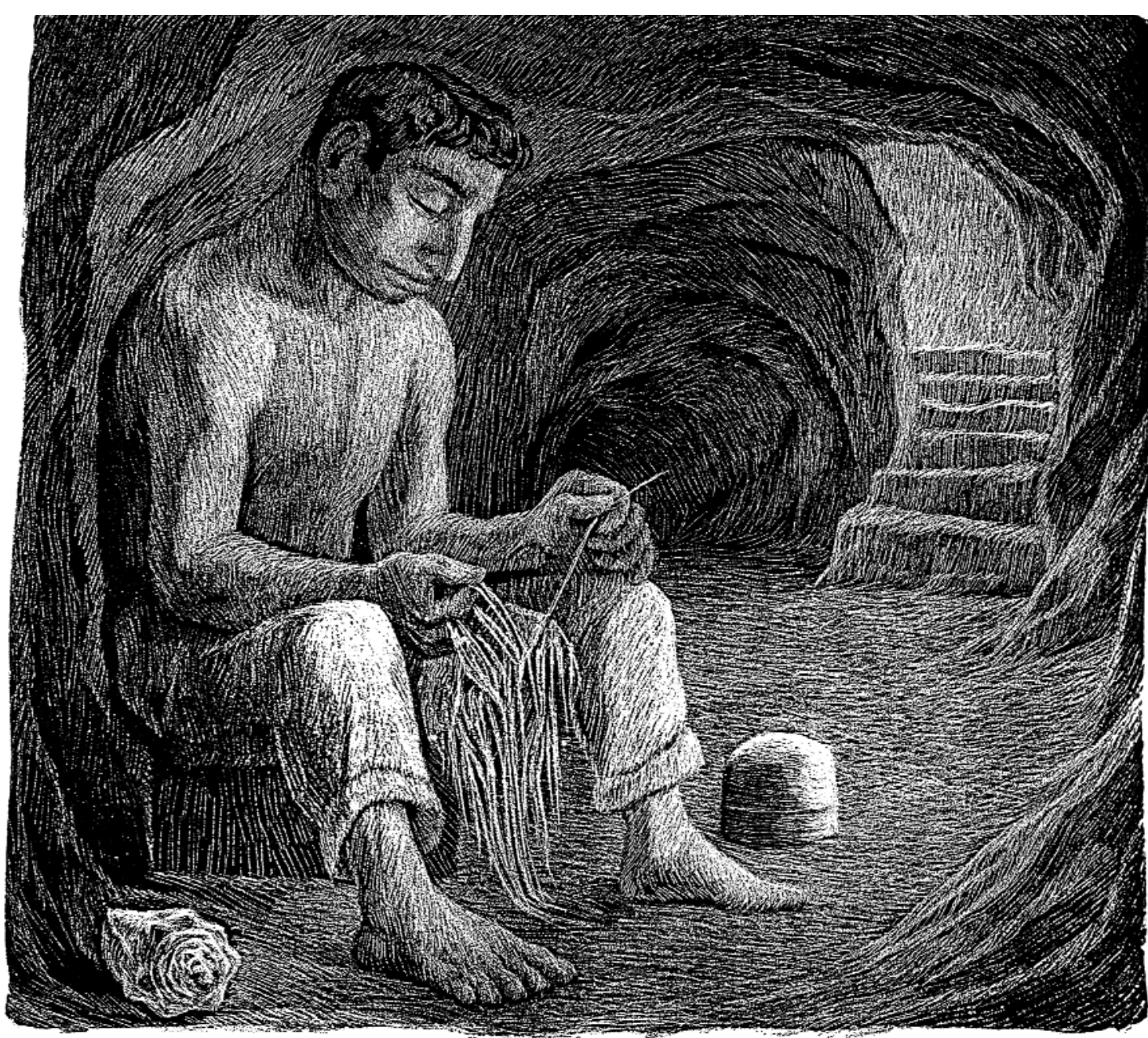

Alfredo Zalce, Hacedor de sombreros, 1945.

gorías culturales que adscriben a una población dependiendo de su desarrollo económico, como la utilización del huipil vs el vestido occidental. Esta forma clasificatoria es inoperante puesto que se puede ser indio y portar el vestido occidental; incluso ser indio y no hablar una lengua indígena. Lo mismo sucede con la principal actividad económica de las localidades rurales, la agricultura, ya que se puede ser campesino sin ser indígena. Las fronteras de estas categorías de clasificación social se diluyen en el panorama del estado; no se sabe muy bien dónde comienzan ni dónde terminan ni a quiénes se refieren; son contextuales pues se aplican a casos específicos que en la interacción social se van produciendo, reforzando ideas previamente construidas. Sirven en determinados momentos para conocer quiénes son aquéllos con los que se interactúa y la forma en que tal interacción deberá llevarse a cabo. ${ }^{7}$

\footnotetext{
${ }^{7}$ En las relaciones interétnicas entre grupos claramente diferenciados desempeña un papel importante el conocimiento previo que los miembros de un grupo poseen sobre los del otro colectivo con el que se encuentran relacionados. No se identifica a la persona como tal sino como parte de un grupo socialmente definido a partir de características diversas que varían dependiendo de las circunstancias y de los contextos en los que se desarrolla la interacción (Goffman, 1997). Las relaciones entre sujetos pertenecientes a grupos diferenciados se conducen a partir de experiencias previas imponiendo con ello a los actores sociales papeles que deben desempeñar.
} 
En México, el indicador comúnmente aceptado para identificar a los miembros de los grupos indígenas que habitan en el territorio nacional ha sido la lengua. ${ }^{8}$ Si bien entre los investigadores sociales existe el consenso de que las cifras estadísticas no reflejan fielmente la realidad social misma (es decir, no están todos los que son), éstas al menos permiten mostrar tendencias de la dinámica poblacional y, en un primer momento, ayudan a bosquejar la situación de los miembros de la etnia maya y las principales problemáticas en las que están inmersos. ${ }^{9}$

CuAdro 1. Población total de la península de Yucatán y población hablante de lengua maya por estado

\begin{tabular}{lcc}
\hline Estado & $\begin{array}{c}\text { Población } \\
\text { total }\end{array}$ & $\begin{array}{c}\text { Hablantes de } \\
\text { lengua maya }\end{array}$ \\
\hline Yucatán & 1658210 & 549532 \\
\hline Campeche & 690689 & 93765 \\
\hline Quintana Roo & 874963 & 173592 \\
\hline Total & 3223862 & 816889 \\
\hline
\end{tabular}

FUENTE: INEGI, Tabulados básicos, 2001.

Los datos censales sobre los habitantes mayas de la península de Yucatán indican que su población ha crecido sustancialmente, como lo demuestra el registro del número de hablantes de esa lengua. Las cifras señalan incluso un dinámico aumento poblacional de portadores de cultura maya, pues en 1970 se consideraba indígena a 454675 habitantes de la península, en tanto que en 1980 los mayas sumaron 665377 personas. Hacia 1990 aumentó a 713 520, y en 2000 el cálculo fue de 816889 pobladores integrantes de esa etnia. Cabe aclarar que, usando otros criterios más amplios que la lengua, como el de residentes en hogares indígenas, el cálculo tiende a elevarse

\footnotetext{
8 Barabas y Bartolomé (1999, I: 11-12) han insistido en los problemas que presenta el manejo de información estadística disponible sobre los grupos étnicos de Oaxaca, debido a varios factores, entre otros: la "dudosa confiabilidad de los datos censales", al mostrar inexplicables cambios en el número de hablantes a través del tiempo; lo inadecuado de los cuestionarios censales con respecto a la realidad social, y de que la unidad de información censal disponible es el municipio. Aquí emplearemos las cifras censales teniendo en cuenta las observaciones señaladas. ${ }^{9}$ El criterio de uso de la lengua maya como único indicador para consignar a la población indígena originaria de esta región conduce con seguridad al subregistro; a pesar de ello, los datos son suficientes para establecer la fuerte permanencia numérica de los mayas.
}

CuADRo 2. Población hablante de lengua maya
del estado de Yucatán, por grupos de edad y sexo
\begin{tabular}{|cccc}
\hline Grupos de edad & Total & Hombres & Mujeres \\
\hline $5-9$ años & 38699 & 19612 & 19087 \\
\hline $10-14$ & 47806 & 24404 & 23402 \\
\hline $15-19$ & 51023 & 25924 & 25099 \\
\hline $20-24$ & 51119 & 25525 & 25594 \\
\hline $25-29$ & 44834 & 22343 & 22492 \\
\hline $30-34$ & 42471 & 21018 & 21453 \\
\hline $35-39$ & 42579 & 20894 & 21685 \\
\hline $40-44$ & 39657 & 19758 & 19899 \\
\hline $45-49$ & 39033 & 19418 & 19615 \\
\hline 50 y más & 152311 & 78422 & 73889 \\
\hline Total & 549532 & 277312 & 272215 \\
\hline
\end{tabular}

FUENTE: INEGI, Tabulados básicos, 2001.

sustancialmente y para 1995 la población indígena estimada de la península yucateca ascendería a 1423907 personas. ${ }^{10}$

El estado de Yucatán concentra a la mayor parte de la población indígena de la península. ${ }^{11}$ En 1990, los hablantes de maya mayores de cinco años sumaron 525264 personas, y en 2000 ascendieron a 549532 . Con el criterio exclusivo de la lengua, la población indígena del estado representaba en 2000 el $37.31 \%$ del total de los habitantes de la entidad mayores de cinco años, considerados en 1472683 personas. $^{12}$

La distribución quinquenal por edad de los hablantes de lengua maya de Yucatán ofrece indicios de los requerimientos educativos, laborales y asistenciales para esa población. Se puede afirmar que 137528 hablantes de maya se encuentran en edad escolar —entre los cinco y los 19 años-, que son potenciales usuarios del sistema educativo en todos sus niveles. Otros 259693 integrantes de la etnia maya se ubican en edad laboral plena —entre 20 y 49 años- y demandan opciones de trabajo e ingresos. Por último, 152311 mayas rebasan los 50 años y mu-

\footnotetext{
${ }^{10}$ Embriz O. y Ruiz M., 2003: 102-103.

${ }^{11}$ Según datos del XII Censo de Población y Vivienda, en el año 2000 los hablantes de lengua maya en Campeche sumaron 93765 personas, en tanto que en Quintana Roo, el número reportado fue de 173592. 12 Estimaciones realizadas por el INI y el CONAPO, basadas en los datos censales de 2000, apuntan que en Yucatán un 59.1\% del total poblacional es indígena.
} 




Fuerte en Nohpop. Guerra de castas, 1901 / Centro de Apoyo a la Investigación Histórica en Yucatán.

chos de ellos forman parte de los llamados adultos mayores que requieren de servicios asistenciales y médicos. ${ }^{13}$

\section{Monolingüismo y bilingüismo}

La mayor parte de la población indígena de la península y del estado de Yucatán es bilingüe, aunque todavía es considerable la cantidad de hablantes monolingües de maya. ${ }^{14}$ La existencia de un creciente bilingüismo en la población indígena de Yucatán es un fenómeno complejo que puede ser explicado por dos situaciones que se contraponen. La primera impulsa la castellanización y tiene que ver con la inserción de la población maya al proceso

${ }^{13}$ La distribución por edades de la población hablante de maya en el estado indica la existencia de una situación que debe considerarse grave y podría denominarse como de envejecimiento del grupo. Esta situación se hace evidente al dibujar la pirámide de edades y sexo, pues la gráfica se aleja de la figura piramidal obligada para la mayoría de los grupos de población para semejarse a una columna, ya que la cantidad de mayahablantes en todos los rangos es similar, a excepción de la cúspide, que agrupa a la población mayor de 50 años. En el 2000, el 27.7\% de los hablantes de lengua maya estaba en el rango de 50 años o más.

${ }^{14} \mathrm{El}$ número de monolingües mayas en el estado, en el año 2000, fue de 48066 personas; los bilingües ascendieron a 497722 (INEGI, 2001). educativo formal. En las últimas décadas, por medio de la educación pública e indigenista se ha procurado la enseñanza del español como lengua nacional entre los menores originarios de ese grupo. El resultado ha sido una pérdida paulatina de los espacios sociales y de uso cotidiano de la lengua maya y como consecuencia se ha abandonado en mucho los necesarios vínculos de los hablantes de la lengua maya con la cultura universal y con el conocimiento científico y especializado. Quienes mantienen el uso de la lengua originaria no tienen acceso mediante ella al acervo acumulado del conocimiento universal y prácticamente sólo pueden entrar en contacto con él a través del empleo del español. La otra situación, por el contrario, refuerza la continuidad del uso de la lengua maya y tiene que ver con la riqueza de esta lengua para mantener con vida la cultura y la explicación que del entorno mantienen sus portadores. Ahora más que nunca se puede afirmar que la cultura maya vive a través de su lengua. Muchos y complejos conocimientos agrícolas, religiosos, ecológicos y de cosmovisión que se emplean tienen su cabal expresión en esta lengua. ${ }^{15}$

\footnotetext{
${ }^{15}$ Berger y Luckmann (1998: 55) han afirmado que la cultura, expresada
} 

de Yucatán por su condición de monolingües o bilingües

\begin{tabular}{lccr}
\hline & Total & Hombres & Mujeres \\
\hline Monolingües & 48066 & 19454 & 28612 \\
\hline Bilingües & 497722 & 256376 & 241346 \\
\hline
\end{tabular}

FUENTE: INEGI, Tabulados básicos, 2001. ten diversos niveles de bilingüismo que oscilan desde un conocimiento más bien rudimentario del español hasta la casi completa pérdida del habla en maya. Para la mayoría el aprendizaje del español es tardío e incompleto, pues comienza a partir de los cuatro o cinco años de edad y se realiza con grandes deficiencias estructurales. El resultado se traduce en inmensas desventajas de los mayas bilingües para afrontar con éxito niveles subsecuentes a la educación básica. Este problema es particularmente evidente en la educación superior incluyendo, desde luego, los posgrados. La desventaja de un bilingüismo tardío e incompleto afecta negativamente, asimismo, la inserción de los indígenas a los mercados de trabajo urbano y especializado.
CUADRO 3. Población hablante de lengua maya del estado

Es importante señalar que entre los mayas yucatecos exis-

nas en México. Especialmente la carencia de una escritura formal con validez legal en la lengua maya, el hecho de que no se traduzcan libros y otros escritos y, sobre todo, que no se provea de educación formal plena en esa lengua, conduce a un aislamiento forzado que amplía las desventajas de los mayahablantes.

\section{Educación e integracionismo}

La información que se ha presentado hace evidente que uno de los mayores problemas que afronta la población indígena del estado de Yucatán es, sin duda, el acceso a la educación escolarizada y especialmente el enfoque con el que se desarrolla la educación indígena existente. Los datos de acceso de los hablantes de lengua indígena a los servicios de la educación pública gratuita son muy ilustrativos. En 1995-1996 en el estado de Yucatán se impartió educación preescolar indígena en 73 municipios y 266 localidades, con un total de 13647 menores atendidos por 569 maestros bilingües, incluidos 246 directores con grupo. Asimismo, para los años citados el programa oficial de primaria indígena cubrió 43 municipios y 173 localidades, con un total de 12955 alumnos atendidos por 517 maestros bilingües, incluyendo 150 directores con grupo. Otros datos son importantes para ilustrar las muy graves deficiencias en los servicios educativos para la población maya. En 1993 sólo existía infraestructura educativa y albergues escolares indígenas en 26 municipios del estado, con 33 escuelas de educación preescolar, 19 de primaria bilingüe, 24 de primaria, 30 de secundaria, cuatro de bachillerato, un establecimiento de educación media, cinco centros de alfabetización y 38 albergues. La información de 2001 refiere un total de 522 escuelas dependientes de la Subdirección de Educación Indígena de la Secretaría de Educación estatal, de las cuales 79 son de educación inicial, 268 de preescolar y 175 de primaria. En total, estas escuelas, a cargo de 557 maestros, atendieron a 34120 menores hablantes de maya. ${ }^{16}$

a través de la vida cotidiana, es vida con el lenguaje que un miembro del grupo comparte con sus semejantes y por medio de él. Sostienen, por tanto, que la comprensión de la lengua es esencial para cualquier comprensión de la realidad cotidiana de un grupo.
16 De este total, 3786 menores cursaron educación inicial, 14737 educación preescolar, 13919 primaria y 1636 albergues. 
A pesar de que más de la tercera parte de la población del estado es mayahablante no existe en Yucatán educación en lengua indígena más allá de la primaria. Es importante destacar que en la mayor parte de las localidades mayas se tiene una organización escolar de grupos multigrados, lo que dificulta el proceso de enseñanza-aprendizaje, y que en muchos pueblos con importante población maya se carece por completo de algún espacio donde se imparta educación indígena.

Desde el punto de vista cuantitativo, los servicios educativos para la población maya todavía son insuficientes, lo que se traduce en la existencia de un importante nivel de analfabetismo en el estado, ya que cerca del $20 \%$ de los habitantes mayas carecen de la instrucción mínima. ${ }^{17}$ Otro dato ilustrativo del índice de este analfabetismo se refiere a los ocho municipios con mayor grado de marginación en el estado. ${ }^{18}$ De 12609 menores entre los seis y 14 años, el $28 \%$ no sabe leer ni escribir. De 28843 habitantes mayores de 15 años, el 35\% está en condición de analfabetismo. La dispersión poblacional, el importante número de localidades con mayoría indígena, pero sobre todo, el hecho de haber relegado a la lengua maya a la condición de segunda lengua, son variables que ayudan a explicar el importante número de analfabetos entre la población maya, con un índice cercano al $20 \%$, un problema que afecta especialmente a las mujeres.

Los datos muestran una clara tendencia a la utilización del sistema educativo público, único al que tienen acceso los mayas, como eje de la política de integración que se ha desarrollado en México para la población indígena en las últimas siete décadas. La educación indígena, que se imparte de forma bilingüe, tiene por objetivo la capacitación integral de los menores de origen indígena para adecuarse a la cultura nacional y otorgar a sus egresados la posibilidad de un acceso al sistema educativo no indígena durante los dos últimos años de la primaria. Sin embargo, es evidente que este sistema sólo ofrece espacio a poco

\footnotetext{
${ }^{17}$ Según estimaciones del INI-CONAPO, un $17 \%$ de la población no posee instrucción alguna; $34.4 \%$ posee primaria incompleta; $17 \%$ posee primaria completa y un $30.9 \%$ tiene algún grado de instrucción después de la primaria (Serrano, Embriz y Fernández, 2002).

18 Estos municipios son Cantamayec, Chemax, Chichimilá, Chikindzonot, Mayapán, Tahdziú, Tekom y Tixcacalcupul.
}

más de la mitad de la población menor hablante de lengua maya en el estado. Una buena parte de esa población, no menor a 55000 según datos de 1995-1996, para tener acceso a cierto nivel de educación debe recurrir de manera directa al sistema no indígena que se desarrolla en español o bien a programas como los que desarrolla el Consejo Nacional de Fomento Educativo que lleva escolaridad a poblaciones apartadas y con escaso número de pobladores y privilegia la educación en español.

En ambos casos, quienes cursan por la educación indígena y quienes entran en forma directa a la educación no indígena o regular, encuentran grandes dificultades para continuar en los niveles de educación media, media superior y especialmente en la educación universitaria y tecnológica. El problema de fondo continúa siendo que los menores mantienen su socialización primera desde el nacimiento en la lengua materna - y por tanto en los parámetros de la cultura maya - en el seno de las familias y de las localidades. Es decir, las nociones básicas que guían la formación del individuo y que le permiten la comprensión de sus diferentes entornos son las propias de su sistema cultural (Berger y Luckmann, 1998). Pero como resultado de la segregación colonial y del integracionismo forzoso auspiciado por el Estado nacional, la sociedad y la cultura maya han quedado reducidas al carácter de entidades locales sin mayor comunicación con el desarrollo del conocimiento mundial y sin mayores conexiones con la cultura universal. Este fenómeno tiende a restringir en grado superlativo los contenidos a los que tienen acceso los individuos durante sus primeros años de vida y genera una grave falta de competitividad al afrontar niveles más complejos de socialización en el sistema educativo formal.

Es importante aclarar que el problema de raíz no es la diferencia lingüística, sino el haber encapsulado a la cultura maya, toda vez que las políticas estatales no han fomentado su desarrollo pleno en el contexto del progreso universal. El resultado de ese complejo problema es la deserción escolar en forma masiva, el bajo rendimiento de los estudiantes y un acceso muy restringido de los jóvenes de origen maya a los niveles de la educación superior con un bagaje muy deficiente para competir en este ámbito. Se puede afirmar que este modelo de edu- 


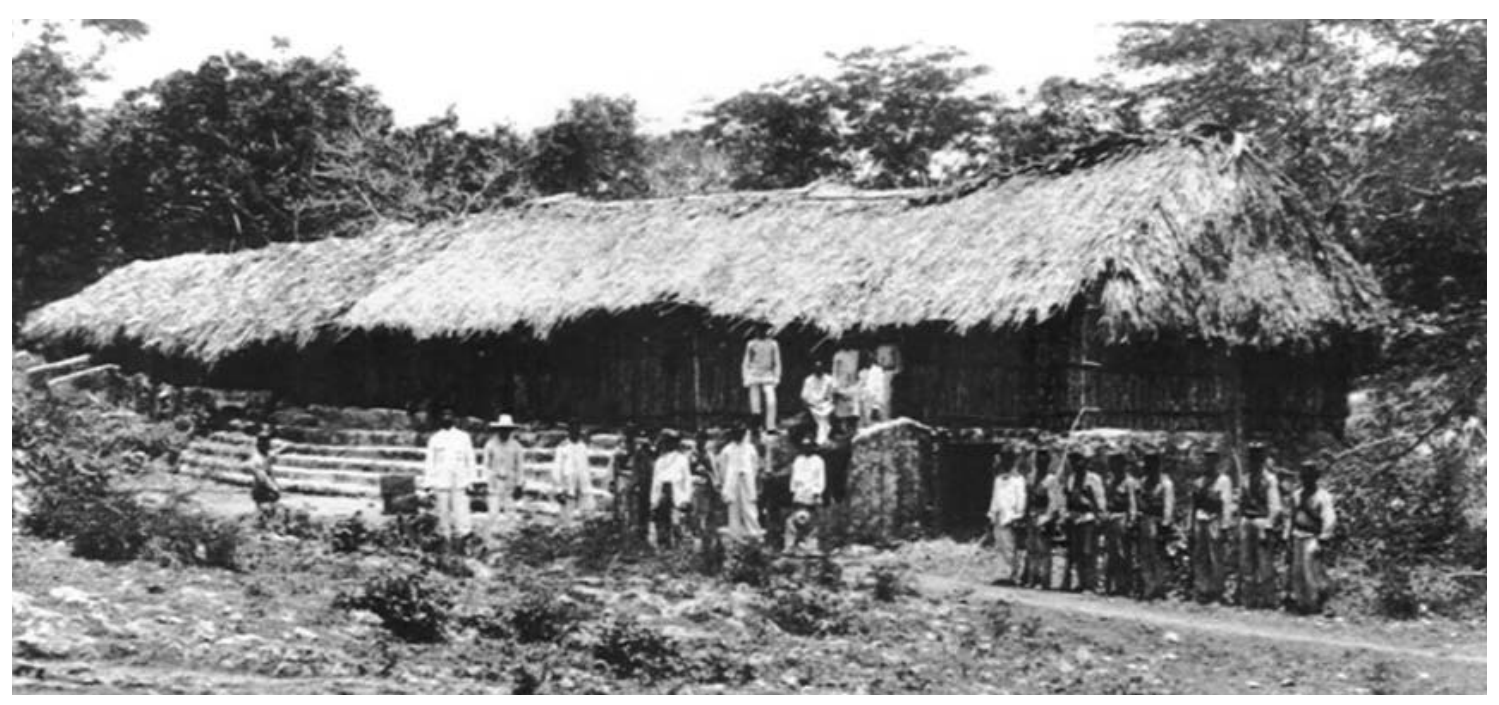

Cuartel de los mayas, hoy hospital general. Santa Cruz de Bravo, 1901 / Centro de Apoyo a la Investigación Histórica en Yucatán.

cación bicultural se ha traducido en la reproducción de grandes niveles de desigualdad y de marginación. ${ }^{19} \mathrm{El}$ resultado es, entonces, la reproducción de economías agrícolas de autosubsistencia, el acceso a posiciones laborales no calificadas con mínimos ingresos monetarios y la pobreza extrema.

\section{Tenencia de la tierra}

La mayoría de la población maya trabaja en la agricultura o en otras actividades del sector primario como la pesca y la ganadería. ${ }^{20}$ Con respecto a la primera actividad, en Yucatán existen actualmente 727 ejidos en posesión de alrededor de 180500 campesinos ejidatarios, muchos

${ }^{19}$ Maldonado (2002: 147-155) indica, para el caso de Oaxaca, que la escuela indígena es productora de doble ignorancia ya que, por un lado, el tiempo que los niños invierten en ella les impide adquirir otros conocimientos propios de su cultura y, por otro, la educación que reciben los convierte en ignorantes funcionales, o sea, en "indios que conocen lo mínimo indispensable de la cultura occidental con lo que podrán moverse con más o menos éxito entre las capas más bajas de las masas explotadas por las élites de la sociedad nacional totalitaria".

${ }^{20}$ Datos del INI y el CONAPO indican que $26.6 \%$ del total de la población indígena del estado se encuentra empleada en el sector primario; un $30.8 \%$ lo está en el secundario y un $42.6 \%$ en el terciario (Serrano, Embriz y Fernández, 2002).

de los cuales están organizados en poco más de 88300 unidades de producción. En la zona indígena del sur, del oriente y del noroeste existen 421 ejidos cuyos integrantes se dedican principalmente a la milpa de temporal, con el sistema de la tumba-roza-quema, para la producción de maíz, frijoles y calabaza. En alrededor de 80 de esos ejidos también se practica la ganadería extensiva y la citricultura. En la zona noroeste, con un reciente pasado henequenero, existen 272 ejidos colectivos que estuvieron prácticamente administrados hasta hace poco por el Banco de Crédito Rural y la Secretaría de la Reforma Agraria. Una combinación de producción henequenera en pequeña escala, de cultivos de maíz, de trabajo asalariado y de migración temporal ha permitido el sustento en estos ejidos en los últimos años. Por último, en lo que se conoce como la zona más tradicional del estado, los municipios de Valladolid y Chemax, existen 36 ejidos que subsisten gracias a la milpa y, en muy pequeña escala, la ganadería extensiva.

Alrededor de un $12 \%$ de los ejidatarios ingresaron al Programa de Certificación de Derechos Ejidales y Titulación de Solares Urbanos. Este programa abarca 21 municipios, la mayoría con fuerte presencia indígena. La información del PROCEDE es ilustrativa de la capacidad de la sociedad maya para adecuar el régimen de tenen- 
cia de la tierra a las condiciones de su entorno, pues si bien la mayor parte de quienes ingresaron al programa optaron por la tierra de uso colectivo, un significativo $42.6 \%$ se decidió por la regularización en parcelas. Hay que aclarar que la opción por las parcelas abarca primordialmente los municipios de la zona oriental dedicada en especial a la ganadería extensiva, como es el caso de Tizimín, y de la todavía llamada zona henequenera, como el municipio de Motul. Sin embargo, hay que apuntar que existen tendencias contradictorias frente a la certificación. Por una parte, los ejidos exitosos con actividad agrícola de mercado, y por otra, los tradicionalistas dedicados al cultivo de maíz, coinciden, aunque por razones distintas, en no aceptar fácilmente la certificación y la parcelización.

\section{Marginación y pobreza}

Con base en los datos anteriores y en la proporción de hablantes de lengua indígena se puede hablar de tres categorías de municipios yucatecos. En la primera se encontrarían 44 municipios en los que la proporción del número de hablantes de maya, con respecto a la población total de cinco años y más, es superior al 70\%. En un segundo grupo estarían otros 44 municipios en los que la población maya es equivalente a la no maya (entre el 30 y el 69\% de hablantes de lengua indígena). Y el tercer grupo lo conformarían 18 municipios en donde los mayas son minoría (menos del $29 \%$ del total poblacional). ${ }^{21}$

Veinte de los municipios ubicados dentro del primer grupo presentan un grado de marginación alto y ocho más presentan un índice muy alto;22 estos últimos poseen una población mayoritariamente maya con índices que

${ }^{21}$ Los municipios con menor número de hablantes de lengua maya se ubican, principalmente, en el norte del estado, lo que sería el litoral costero, así como los municipios del área metropolitana de la ciudad de Mérida. Los municipios con un 30-69\% de mayahablantes se encuentran en una franja intermedia, centro-norte, en la que estarían los que pertenecieron a la llamada zona henequenera, prolongándose hasta el nororiente del estado. Por último, los municipios mayoritariamente habitados por indígenas estarían ubicados, básicamente, en la parte sur y suroriente de Yucatán.

22 Para el 2000, en los municipios de muy alta marginalidad habitaban 42086 hablantes de lengua maya y en los de marginalidad alta existían 114641 (INEGI, 2001). van del 97.1 al 99.6\% (Cantamayec y Tahdziú, respectivamente) de hablantes de esta lengua con respecto al total de la población de cinco años y más. En los municipios ubicados en esta categoría es perceptible una importante distribución espacial de la población y un patrón de asentamiento disperso con predominio de pequeñas localidades, pues en 2000 se consignaron 1082 asentamientos, 844 de los cuales no sobrepasaba los 100 habitantes.

En la segunda categoría, en que las poblaciones indígena y no indígena tienden a ser equivalentes, se encuentran 44 municipios, en los que los mayas representan entre el 30 y el $69 \%$ de la población total. En este caso, en el año 2000, los hablantes de lengua maya sumaban 214 549 personas distribuidas en 1637 localidades. Diez de estos municipios (cuyas proporciones de hablantes de maya con respecto al total de cinco años y más oscilaban entre el 52.8 y el 67.9\%) presentaban un índice de marginación alto, mientras que los 34 restantes estaban considerados con un grado de marginación media. Por último, la minoría indígena se registra en 18 municipios yucatecos que reportaban menos del $30 \%$ de población indígena estimada. En éstos habitaban, en el año 2000, un total de 121182 hablantes de lengua maya agrupados en 622 localidades. Trece de estos municipios tenían un índice de marginación medio; tres de ellos presentaban una marginación baja y sólo dos (Mérida entre ellos) poseía un índice de marginación muy bajo. ${ }^{23}$ No obstante, estos últimos datos esconden una realidad más compleja, ya que en municipios con marginalidad media e incluso baja los mayas se encuentran en condiciones de desventaja y de mayor grado de marginación con respecto a la población no india. Los distintos indicadores que definen la marginalidad se manifiestan entre los mayas con crudeza, ya sea salud, educación, servicios o ingresos.

La información anterior muestra que la población maya posee un alto grado de marginación ${ }^{24}$ y evidencia la

\footnotetext{
${ }^{23}$ Es necesario señalar que la ciudad de Mérida ha concentrado secularmente a una importante población maya. El XII Censo de Población y Vivienda registró que 92465 personas (de un total de 705 055) hablaban lengua maya. A pesar de que este número representa sólo el $13.1 \%$ del total poblacional del municipio, en Mérida habita cerca del $17 \%$ del total de hablantes de maya del estado.

${ }^{24}$ Según el Consejo Nacional de Población (1993), la población mar-
} 


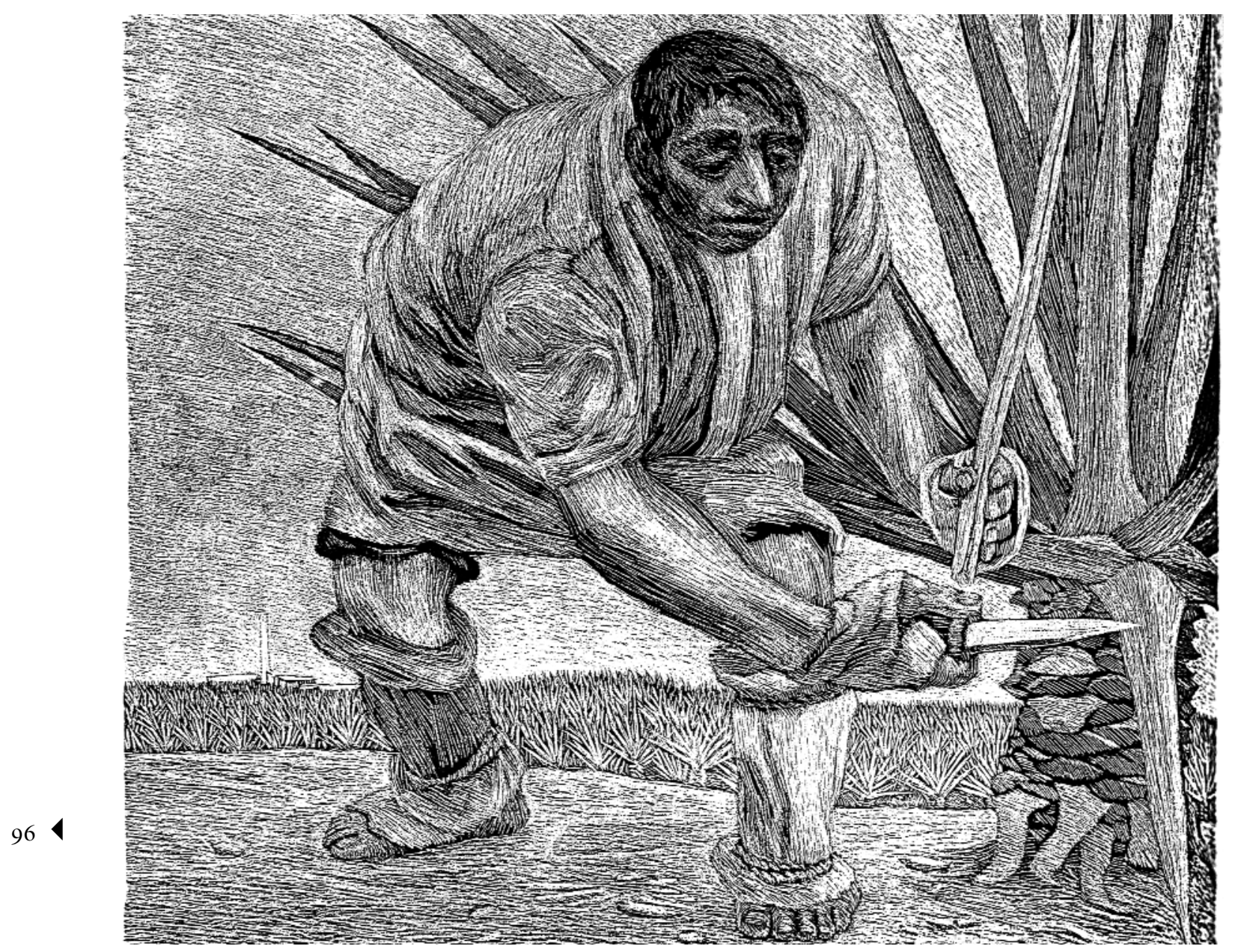

Alfredo Zalce, Cortador de henequén, 1945.

situación vulnerable en que se encuentran los mayas de Yucatán.

Uno de los problemas más recurrentes al momento de planificar políticas de combate a la pobreza es el patrón disperso de asentamiento de la población. Éste se hace patente, por ejemplo, en el hecho de que en los ocho municipios de mayor grado de marginalidad y pobreza del estado de Yucatán — que según el censo de 2000 en conjunto tienen 50868 habitantes- existen 325 localidades, de las que 280 no rebasan las 99 personas cada una. Otras 32 localidades comportan entre 100 y 999 pobladores, y

ginada es aquella que se encuentra excluida total o parcialmente del acceso y disfrute de los bienes y servicios y de la participación en asuntos públicos. cinco más concentran entre 1000 y 1999 habitantes. Sólo siete localidades rebasan el tamaño poblacional anterior y, entre ellas, una es superior a los 5000 habitantes.

El patrón disperso de asentamiento se adecua bien a las labores agrícolas que tradicionalmente realiza la población maya, especialmente el cultivo de maíz, y a otras actividades secundarias, pero también es un resultado histórico de la migración de habitantes de los pueblos hacia las haciendas durante el siglo XIX y de la dotación de tierras para la creación de los ejidos en las décadas de 1920 a 1960. Tal distribución poblacional ha significado, sin embargo, grandes dificultades en la construcción de infraestructura y de equipamiento en la mayor parte de las localidades con mayoría indígena. Asimismo, la dispersión de los asentamientos ha dificultado el acceso de sus 
habitantes a los servicios básicos de educación, salud y bienestar, que se concentran en las ciudades y en las localidades de mayor número de habitantes. Una de las mayores deficiencias es, sin duda, una red de comunicaciones carreteras todavía insuficiente, así como el escaso desarrollo de la telefonía y otros medios de comunicación.

Otro de los problemas más apremiantes es la carencia de asistencia médica. En los ocho municipios con mayor grado de marginación, por ejemplo, el 94.7\% de sus habitantes no cuenta con ningún tipo de derechos asistenciales de salud, y sólo el 3.5\% es derechohabiente del IMSS y otro $0.8 \%$ lo es del ISSSTE.

\section{A MANERA DE CONCLUSIÓN}

Cualquier fuente de datos a la que se recurra nos brindará información que dibuja una población altamente marginada. Así por ejemplo, un diagnóstico realizado en el año 2000 refiere que un $50 \%$ de la población maya mayor de 15 años no tiene ni tendrá primaria completa, que el $30 \%$ no posee agua entubada, que en el $60 \%$ de las viviendas se vive en hacinamiento y que el $20 \%$ de éstas tiene pisos de tierra. Asimismo, se apunta que la gente se sigue muriendo de las enfermedades típicas de la pobreza, como la diarrea y las infecciones de las vías respiratorias altas. En 2000 el 32.2\% de la población maya obtenía ingresos menores a un salario mínimo y otro $36.7 \%$ ganaba menos del equivalente a dos salarios mínimos. ${ }^{25}$ Otro de los problemas asociados a la marginación es el alcoholismo, pues de acuerdo con una encuesta realizada en 1997 el 65\% de los pobladores de entre diez y 65 años consumía bebidas alcohólicas.

La marginación y pobreza son realidades lacerantes que han acompañado a la población maya de Yucatán, y que se han agravado en las últimas décadas. Éstas han sido resultado de las dos políticas gubernamentales que se han aplicado a lo largo de la historia a la población maya yucateca, la segregación colonial y el integracionismo nacional. Ambas constriñeron a los portadores de la cultura

\footnotetext{
25 Serrano, Embriz y Fernández (2002).
}

maya al ejercicio de su riqueza cultural en el ámbito estrictamente local, sin facilitar un intercambio cognoscitivo amplio con el exterior. La pérdida de la escritura de la lengua maya se tradujo en una de las mayores desventajas para quienes permanecieron como monolingües y también para los bilingües, pues reforzó el aislamiento y el deterioro de los mecanismos de sobrevivencia cultural.

La castellanización forzada, incompleta en la mayoría de los casos, despojó a los habitantes mayas de buena parte de sus bases conceptuales, pero al mismo tiempo, no fue capaz de brindarles cabalmente los conocimientos necesarios de la cultura occidental, para poder relacionarse en mejores condiciones en ámbitos externos a sus campos de acción local. Uno de los problemas más graves de la historia reciente ha sido el desfase entre una socialización primaria realizada durante los primeros años de vida de los menores en el seno de la familia maya y en su propia lengua y una socialización secundaria que se efectúa en instituciones sociales rígidas como la escuela, que procuran la integración de esos menores a una cultura nacional homogénea en lengua castellana. El resultado de la ruptura del proceso de socialización plena en la propia cultura a corta edad, enfrentada con la socialización secundaria que no aporta siquiera las bases lingüísticas mínimas de la lengua "nacional", se traduce en una situación de amplia desventaja para los habitantes mayas. Ese proceso sólo ha conducido a la carencia de preparación educativa, a la marginación, a la falta de oportunidades y de competencia y a la pobreza.

Una nueva política para la atención de la población maya del estado de Yucatán deberá sustentarse en dos principios fundamentales. El primero es reconocer que se tiene una deuda histórica con esta población y se debe por tanto atender el reclamo de justicia social. El otro principio es el reconocimiento de que, a pesar de la situación de marginación que ha enfrentado a lo largo de su historia, la sociedad maya ha tenido y tiene la capacidad y la fuerza vital para reproducirse como grupo, manteniendo la dinámica de su propio acervo cultural y su identidad, y asimilando al mismo tiempo el contexto de la globalización. Hay que decir que en el diseño de las políticas públicas dirigidas a los mayas yucatecos es imprescindible dejar de lado las ansiedades del nacionalismo inte- 
gracionista como precepto fundamental. A la igualdad jurídica de lenguas debe corresponder la igualdad de posibilidades de capacitación y de oportunidades colectivas e individuales. El ideal, consideramos los autores de este artículo, debe centrarse en un sistema educativo que armonice la socialización primaria de los menores mayas con la instrucción formal subsiguiente, ampliando la escolaridad que se efectúa en la lengua maya y conjugándola con la enseñanza gradual del español y de otras lenguas. Se trata de generar una institución social que pueda impulsar el reforzamiento del maya como lengua formal y escrita y que pueda, por tanto, ser el vehículo de intercambio de conocimientos de sus hablantes con las demás culturas del mundo. Una institución de este tipo sólo podrá lograr su concreción a largo plazo, pues implica el cambio estructural de modelos arcaicos de educación indígena y la inversión de grandes recursos humanos y económicos.

\section{Bibliografía}

Barabas, Alicia y Miguel Bartolomé (coords.), 1999, Configuraciones étnicas en Oaxaca. Perspectivas etnográficas para las autonomías, 3 tomos, INAH, INI, México.

Berger, Peter y Thomas Luckmann, 1998, La construcción social de la realidad, Amorrortu, Buenos Aires.

Bracamonte y Sosa, Pedro, 2003, Los mayas y la tierra. Jurisdicción y propiedad indígena en el Yucatán colonial, CIESAS, Porrúa, ICY, México.

—_, 1993, Amos y sirvientes. Las haciendas de Yucatán, 17891860, UDAY, Mérida.

Cardoso de Oliveira, Roberto, 1992, Etnicidad y estructura social, CIESAS, México.

Consejo Nacional de Población, 1993, Indicadores socioeconómicos, índice y grado de marginación a nivel municipal, CONAPO, México.

Cook, Sherburne y Woodrow Borah, 1978, Ensayos sobre historia de la población: México y el Caribe, t. II, Siglo XXI, México.

Embriz Osorio, Arnulfo y Laura Ruíz Mondragón, 2003, "Los indicadores socioeconómicos de los pueblos indígenas y la planeación de la política social en México", en François Lartigue y André Quesnel (coords.), Las dinámicas de la población indígena en México, CIESAS-IRD-Porrúa, México, pp. 85-114.
Farriss, Nancy M., 1992, La sociedad maya bajo el dominio colonial. La empresa colectiva de la supervivencia, Alianza Editorial, Madrid.

_, 1983 , "Propiedades territoriales en Yucatán en la época colonial", Revista de la Universidad de Yucatán, núm. 146, Mérida.

García Bernal, Manuela Cristina, 1978, Yucatán: Población y encomienda bajo los Austrias, EEHAS, Sevilla.

—_, 1972, La sociedad de Yucatán, 1700-1750, EEHAS, Sevilla.

Gerhard, Peter, 1991, La frontera sureste de la Nueva España, UNAM, México.

Goffman, Erving, 1997, La presentación de la persona en la vida cotidiana, Amorrortu, Buenos Aires.

Grimberg, León y Rebeca Grimberg, 1971, Identidad y cambio, Kargieman, Buenos Aires.

Güémez Pineda, Arturo, 2001, Los mayas ante la emergencia del municipio y la privatización territorial, Yucatán, 18121847, tesis doctoral, Zamora, Michoacán.

INEGI, 2001, Tabulados básicos. Estados Unidos Mexicanos. XII Censo General de Población y Vivienda, México, INEGI.

Instituto Nacional Indigenista, 2000, Estado del desarrollo económico y social de los pueblos indígenas de México, 19961997. Primer informe, 2 tomos, INI-PNUD, México.

Herkovits, Melville, 1969, El hombre y sus obras, FCE, México.

Maldonado Alvarado, Benjamín, 2002, Los indios en las aulas. Dinámica de dominación y resistencia en Oaxaca, INAH, México.

Mead, Margaret, 1976, "Our Educational Emphasis in Primitive Perspective", en J. Middleton (ed.), From Child to Adult: Studies in Anthropology of Education, University of Texas Press, Austin.

Melucci, Alberto, 1982, L'invenzione del presente. Movimenti, identità, bisogni individuali, Societè Editrice Il Mulino, Bolonia.

Patch, Robert W., 1993, Maya and Spaniard in Yucatan, 16481812, Stanford University Press.

Roys, Ralph L., 1957, The Political Geography of the Yucatan Maya, Carnegie Institution of Washington, Washington.

_ 1943, The Indian Background of Colonial Yucatan, Carnegie Institution of Washington, Washington.

Serrano, Enrique, Arnulfo Embriz y Patricia Fernández (comps.), 2002, Indicadores socioeconómicos de los pueblos indígenas de México, 2002, INI, CONAPO, Programa de las Naciones Unidas para el Desarrollo, México.

Solís Robleda, Gabriela, 2003, Bajo el signo de la compulsión. El trabajo forzoso indígena en el sistema colonial yucateco, 1540-1730, CIESAS, Porrúa, ICY, México.

Wells Allen y Gilbert M. Joseph, 1996, Summer of Discontent. Seasons of Upheaval. Elite Politics and Rural Insurgency in Yucatan, 1876-1915, Stanford University Press. 